\title{
Ischemia-Reperfusion Injury in Sickle Cell Disease
}

\section{From Basics to Therapeutics}

\author{
Junaid Ansari and Felicity N.E. Gavins
}

From the Department of Molecular \& Cellular Physiology, Louisiana State University Health Sciences Center Shreveport, Shreveport, Louisiana

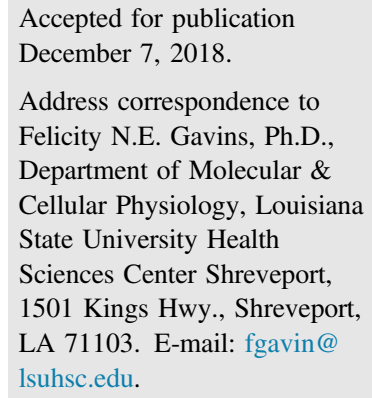

\begin{abstract}
Sickle cell disease (SCD) is one of the most common hereditary hemoglobinopathies worldwide, affecting almost 400,000 newborns globally each year. It is characterized by chronic hemolytic anemia and endothelial dysfunction, resulting in a constant state of disruption of the vascular system and leading to recurrent episodes of ischemia-reperfusion injury (I/RI) to multiple organ systems. I/RI is a fundamental vascular pathobiological paradigm and contributes to morbidity and mortality in a wide range of conditions, including myocardial infarction, stroke, acute kidney injury, and transplantation. I/RI is characterized by an initial restriction of blood supply to an organ, which can lead to ischemia, followed by the subsequent restoration of perfusion and concomitant reoxygenation. Recent advances in the pathophysiology of SCD have led to an understanding that many of the consequences of this disease can be explained by mechanisms associated with I/RI. The following review focuses on the evolving pathobiology of SCD, how various complications of SCD can be attributed to I/RI, and the role of timely therapeutic intervention(s) based on targeting mediators or pathways that influence I/R insult. (Am J Pathol 2019, 189: 706-718; https://doi.org/10.1016/j.ajpath.2018.12.012)
\end{abstract}

Sickle cell disease (SCD) includes a group of inherited disorders caused by mutations in the hemoglobin subunit $\beta .{ }^{1}$ The molecular defect was discovered by Pauling and Itano and later described by Ingram almost 6 decades ago. ${ }^{1}$ The prominence of sickle hemoglobin was seen in Africa, the Middle East, and India several thousand years ago. These areas are highly endemic to malaria-causing protist (Plasmodium falciparum), and sickle cell trait confers a survival advantage and relative resistance against malaria attributable to balanced polymorphism. However, patients with homozygous disease (HbSS) have severe outcomes and may develop lethal complications attributable to falciparum malaria. ${ }^{2}$ Today, SCD has a measurable health and economic impact in the United States and worldwide. This inherited disease is found in 1 of every 365 African Americans and is responsible for approximately 113,000 hospitalizations and $\$ 488$ million in costs annually. ${ }^{3}$ The clinical hallmark of SCD is episodes of acute pain and other common manifestations, including cerebrovascular events, such as transient ischemic attacks, ischemic strokes [including silent cerebral infarcts (SCIs)], intracerebral hemorrhages, acute chest syndrome (ACS), pulmonary hypertension $(\mathrm{PH})$, bacterial infections, splenic infarcts, and progressive multiorgan dysfunction syndrome. ${ }^{3}$ This review focuses on ischemia-reperfusion injury (I/RI) in SCD with the main emphasis on the immunopathology (neutrophils and platelets) and discusses various I/RI-associated SCD clinical outcomes and therapeutic interventions.

\section{Pathobiology of SCD}

SCD was originally considered to be a disease of abnormal erythrocyte polymerization, but in recent years the trend has shifted toward a more complex pathophysiologic makeup, consisting of a polymerization defect, disrupted endothelial

Supported by the NIH National Heart, Lung, and Blood Institute grant 1R01HL134959-01A1 (F.N.E.G.)

Disclosures: None declared. 
and cellular state, and resultant vasculopathies and organ damage (Figure 1). ${ }^{3-5}$

\section{Defective Globin Synthesis}

SCD is caused by a mutation in the $\beta$-globin gene that changes the sixth amino acid from glutamic acid to valine. ${ }^{1}$ This mutation produces a hydrophobic motif in the deoxygenated hemoglobin $\mathrm{S}(\mathrm{HbS})$ tetramer that results in binding between the $\beta_{1}$ and $\beta_{2}$ chains of two hemoglobin molecules. ${ }^{5}$ The resultant crystallization produces a polymer nucleus that grows and fills the erythrocyte, disrupting its architecture and flexibility and promoting cellular dehydration and decreasing ATP content ${ }^{6}$ with physical and oxidative/nitrosative stress. ${ }^{7}$ HbSS disease (the focus of this review) is the most common type of SCD occurring through inheriting copies of the $H b S$ gene homozygous for the sickle mutation..$^{5}$ Inheriting only $1 \mathrm{HbS}$ gene results in a less severe phenotype termed HbAS (heterozygote). ${ }^{5}$

\section{Red Cell Deformability and Hemolysis in SCD}

$\mathrm{HbS}$ polymerization results in altered erythrocyte biology that significantly affects red blood cell (RBC) membrane stability, increasing RBC-dependent cellular interactions, causing hemolysis, and reducing the lifespan of sickle erythrocytes. ${ }^{5,8}$ These effects are more pronounced under deoxygenated conditions, resulting in phosphatidylserine exposure to outer RBC surface. ${ }^{5}$ Because of the abnormal sickle shape, sickle red blood cells (SS RBCs) are not able to traverse small capillaries and thus stick to the postcapillary endothelial surface via RBC adhesion molecules, such as CD36 and integrin $\alpha_{4} \beta_{1},{ }^{9}$ where they provoke unpredictable episodes of microvascular occlusion and premature RBC destruction (hemolytic anemia), resulting in acute painful crisis. ${ }^{10}$

Hemolysis is driven by abnormal $\mathrm{HbS}$ polymerization and promotes inflammation by scavenging nitric oxide and metabolizing its precursor arginine, leading to an oxidative/ nitrosative stress state. ${ }^{11}$ The resultant heme loaded microparticles get attached to the endothelium and increase the expression of adhesion molecules, thus promoting leukocyte recruitment and subsequent inflammation. ${ }^{12}$ Heme-bound iron stimulates expression of placental growth factor in erythroid cells, which contributes to pulmonary vasoconstriction and right ventricular hypertrophy, resulting in $\mathrm{PH}$ in SCD. This ubiquitously expressed molecule promotes Toll-like receptor 4 (TLR4) signaling in endothelial cells and macrophages, activating NF- $\mathrm{KB}$ and triggering vasoocclusion through Weibel-Palade body degranulation and adhesion molecule expression in SCD. ${ }^{13,14}$ Heme also stimulates neutrophils to release their extracellular traps in $\mathrm{SCD} .{ }^{15}$ Although the mechanism is currently unknown, it has been suggested to be linked with reactive oxygen species (ROS) generation in neutrophils (Figure 1). ${ }^{16,17}$ Furthermore, heme can act as a chemotactic molecule or by producing leukotriene B4 by macrophages, thereby inducing neutrophil migration. ${ }^{15}$

\section{Endothelial Dysfunction and Chronic Inflammation}

The microvasculature in SCD assumes a proinflammatory, procoagulant, and prothrombotic state, ${ }^{18}$ with the endothelium itself playing a significant role in both initiating and maintaining the disruptive state in SCD. ${ }^{10,18}$ The hyperactive endothelium in SCD leads to an enhanced RBC and neutrophil adhesion, resulting in slowed flow and sickling in postcapillary venules (retrograde logjamming), and subsequent vaso-occlusion and ischemia ${ }^{18}$ (Figure 1). Evidence that SS RBCs may induce endothelial dysfunction has been obtained in vitro as well as in vivo models. ${ }^{9}$ For example, endothelial adherent SS RBCs and decreased nitric oxide availability increase expression of adhesion molecules, such as vascular cell adhesion molecule (VCAM)-1 and selectins (eg, P-selectin). In addition, damaged RBCs release hemoglobin, which is oxidized to methemoglobin. Methemoglobin is unstable and as such rapidly releases free heme, which can activate the underlying endothelium. ${ }^{14,15}$ In addition, inflammatory mediators, such as interleukin (IL)-6, monocyte chemoattractant protein-1, and platelet-activating factor, are also released from an activated endothelium in SCD and other disease states. ${ }^{5,18,19}$

The endothelium in SCD also plays a key role in driving thromboinflammatory responses by releasing prothrombotic microparticles and tissue factor from circulating endothelial cells. ${ }^{18,20}$ Additional factors include decreased thrombomodulin, tissue factor pathway inhibitor, and von Willebrand factor. ${ }^{18}$ SCD microvasculature is also highly proangiogenic, which has been attributed to the hypoxic environment and increased levels of various proangiogenic factors, including vascular endothelial growth factor, placental growth factor, angiopoietin-1, angiopoietin-2, and erythropoietin in the circulation. ${ }^{18,21}$ For further reading about the role of the endothelium in SCD, please refer to the review by Hebbel et al. ${ }^{18}$

\section{I/RI in SCD}

I/RI is a well-known phenomenon associated with microvascular dysfunction that occurs in a wide range of pathologic conditions, including SCD. ${ }^{22} \mathrm{I} / \mathrm{RI}$ is fundamentally divided into two discrete phases composed of an initial ischemic insult attributable to vaso-occlusion followed by reperfusion, which consists of a pronounced proinflammatory response both locally and remotely (called reperfusion injury), resulting in microvascular dysfunction. $^{23,24}$ The extent of I/RI dysfunction depends on the vascular system involved, underlying comorbidities, and most importantly the magnitude and the duration of ischemia. ${ }^{24}$ Hence, prompt treatment for ischemic events is paramount in I/RI-based complications. ${ }^{24}$ 
At a cellular level, prolonged ischemia and vaso-occlusion trigger anerobic metabolism and lactic acid production, resulting in ATP depletion and intracellular acidosis. As a consequence, ATPases (eg, sodium-potassium ATPase) are inactivated, contributing to an increase in intracellular and mitochondrial calcium (calcium overload) attributable to dysfunctional calcium ion efflux and reduced reuptake of calcium ion by the endoplasmic reticulum. ${ }^{24}$ Concomitantly, excessive production of ROS and calcium overload results in the opening of the mitochondrial permeability transition pore, further reducing ATP levels. ${ }^{24}$ Xanthine oxidase, which has a significant impact on I/RI, is formed from xanthine dehydrogenase under hypoxic conditions and ATP catabolism. Release of xanthine oxidase allows superoxide and hydrogen peroxide production, initiating the overall I/RI. ${ }^{25}$ The univalent reduction of molecular oxygen in I/RI results in the

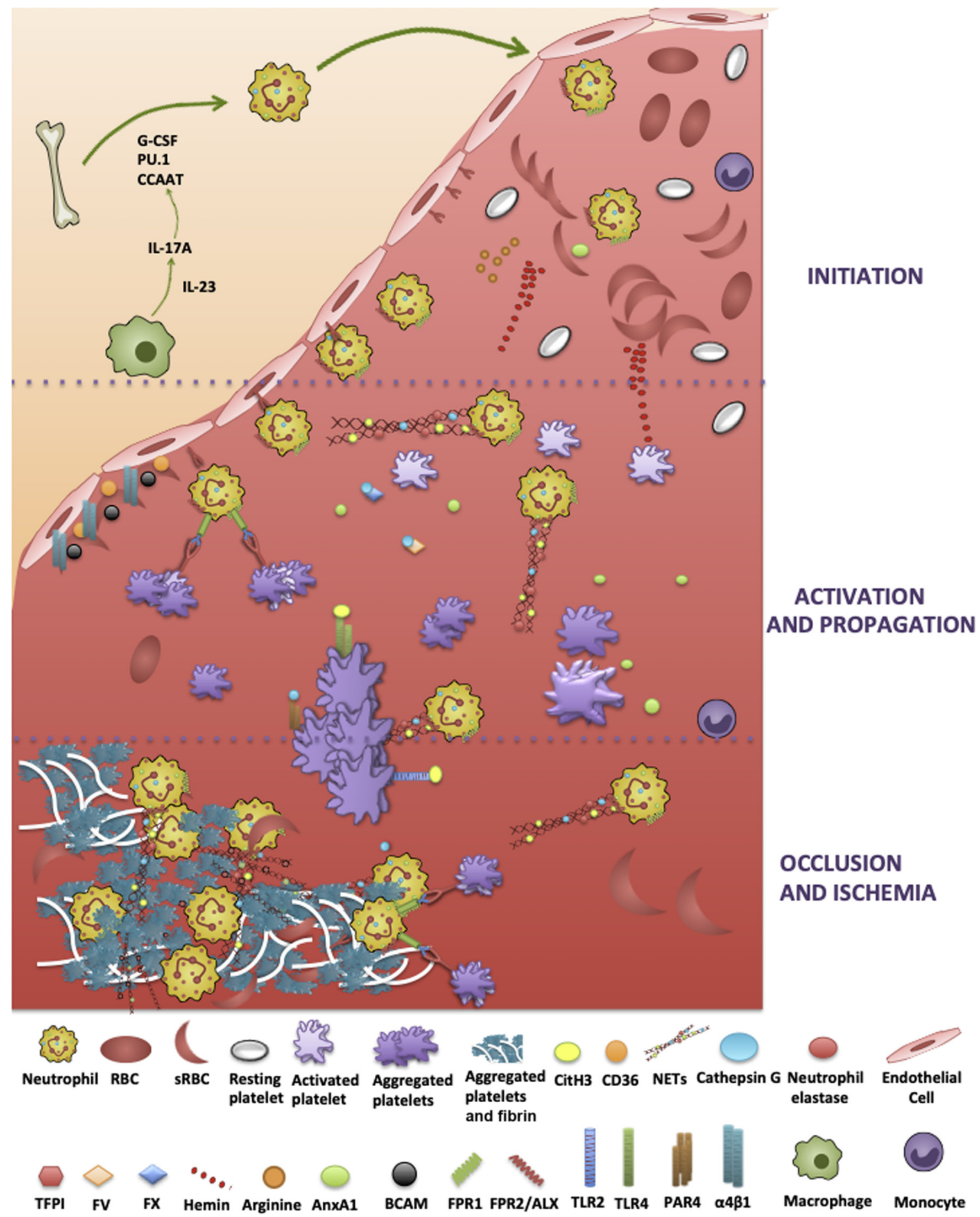


production of primary ROS superoxide anion radical and can directly oxidize various biomolecules and inactivate enzymes, initiate apoptosis, enhance proinflammatory stimuli, modify the expression of adhesion molecules on the surface of leukocytes and endothelial cells, and promote nitric oxide biodeficiency. ${ }^{22,24}$ Tissue hypoxia and ROS production during ischemia activate and recruit cells of innate and adaptive immune system to the affected site, mainly via involvement of signaling events through pattern recognition molecules (especially TLRs, such as TLR4) ${ }^{22}$ and production of IL-17, respectively. ${ }^{22}$ Moreover, the release of proinflammatory mediators in the ischemic area, such as ROS and cytokines/ chemokines from activated endothelium and tissue-resident macrophages and mast cells, activates and recruits leukocytes (eg, neutrophils, monocytes, and lymphocytes). ${ }^{26}$ In addition, there is abundant evidence that now suggests a role of platelets in I/RI. On tissue injury, platelets acquire an activated phenotype via glycoprotein Iba interaction with endothelial P-selectin as well as von Willebrand factor and aggregate and release platelet-derived mediators. ${ }^{27}$ Recent evidence mainly from indirect data that target $\mathrm{T}$ cells (eg, immunosuppressive agents) has suggested a modulatory role of antigen-specific T cells and independent responses in I/RI by mechanisms that are not yet well elucidated. ${ }^{28}$ Finally, the role of the complement system in I/RI is known to involve both classic and alternative pathways. ${ }^{26}$

The mechanisms and widespread cellular and tissue responses known in I/RI described above may explain SCDassociated microvascular complications. I/RI in SCD can lead to endothelial dysfunction ${ }^{29}$ through a deposition of xanthine oxidase, cyclooxygenase, uncoupled endothelial nitric oxide, NADPH oxidase, cytochrome p450, and the mitochondrial electron transport chain, all of which result in an increased vascular production of superoxide. ${ }^{10,30}$ These events help in part to explain the risk of episodic pulmonary arterial vasoconstriction attributable to exaggerated response to unrelated potential vasoconstrictors (eg, hypoxia, platelet activating factor, and incremental hemolytic rate).

\section{Neutrophil Activation and Cellular Cross-Talk in SCD}

Leukocytes (most notably neutrophils) have been implicated in the pathogenesis of SCD and in the genesis of the proinflammatory and prothrombotic phenotype associated with this disease. ${ }^{4,16}$ These immune cells have more complex roles beyond that of just immune surveillance and being first responders in innate immunity. Neutrophils also play key roles in chronic inflammatory conditions, adaptive immune responses, and cancer biology. ${ }^{31}$

Neutrophilia has long been considered a risk factor in SCD and positively correlates with early death, SCIs, hemorrhagic strokes, and ACS. ${ }^{3}$ Reduction of neutrophil count with the use of hydroxyurea markedly decreases the frequency of painful crisis and ACS in moderate and severe SCD. ${ }^{4}$ Neutrophils in SCD also have an activated phenotype with lower levels of $\mathrm{L}^{-}$ selectin (CD62L) and higher levels of CD64. ${ }^{32}$ Various in vivo studies have found that SS RBCs bind to neutrophils via up-regulation of $\alpha \mathrm{MB} 2$ (Mac-1) and E-selectin. ${ }^{4}$ Neutrophil heterogeneity in patients with SCD is also explained by microbiota regulation via danger-associated molecular patterns, ATP, and pattern recognition receptors. ${ }^{32}$ Broad-spectrum antibiotics promote better blood rheology and prolonged survival by depleting microbiota, normalizing the number of aged neutrophils, and reducing the production of neutrophil extracellular traps (NETs). ${ }^{32}$ Moreover, antibiotic use is known to cause a significant reduction in neutrophil adhesion and Mac-1 activation. ${ }^{32}$ For example, historical data with penicillin prophylaxis, which is commonly given to functionally asplenic patients, to mitigate vaso-occlusive crises (VOCs) in SCD. ${ }^{33}$

Figure 1 Proposed overview of the vascular immunopathology of sickle cell disease (SCD). The A6T mutation in the $\beta$-globin gene causes a G6V mutation in the globin polypeptide, leading to the deoxygenated hemoglobin S (HbS) variant. When red blood cells (RBCs) are deoxygenated, HbS polymerizes and the cells take on a sickle phenotype and express adhesion molecules, such as CD36, which mediate attachment with the endothelium. Hemolysis of the sickled cells produces heme microparticles and arginase into the plasma and scavenge nitric oxide and stimulates the release of adhesion molecules, such as intracellular adhesion molecule, vascular cellular adhesion molecule, P-selectin, and E-selectin. Tissue resident macrophages and dendritic cells secrete interleukin (IL)-23, causing $T$ cells to release IL-17A, which stimulates the secretion of granulocyte colony-stimulating factor (G-CSF) to activate neutrophil production. The process of neutrophil maturation is under the control of mainly two transcription factors (PU.1 and CCAAT). Neutrophils adhere and roll along the endothelium through selectin and integrin interactions in the direction of blood flow and are activated by chemokines along the endothelial layer. DAMPs (eg, ATP, high mobility group 1) trigger Toll-like receptor (TLR)-4 and induce an inflammatory response with the secretion of cytokines and chemokines. They also send activation signals to neutrophils and modulate their phenotype (aged neutrophils) that promote sickle cell vaso-occlusion. Activated platelets cause neutrophils to release chromatin and granule proteins to form neutrophil extracellular traps (NETs) and capture sickle RBCs (sRBCs). After activation from glycolipids derived from the tissue damage, invariant natural killer T (iNKT) cells cause further neutrophil recruitment and inflammation through production of interferon- $\gamma$ and CXCR3 chemokines. SRBCs have phosphatidylserine externalization and express $\beta_{2}$-adrenergic receptors, which activate their procoagulant nature and adhesion properties, respectively. The subsequent responses consist of continuous accumulation of leukocytes, platelets, and RBCs with the activation of the coagulation cascade. These interactions may be mediated by the production of various proinflammatory and prothrombotic mediators, such as cathepsin G, neutrophil elastase, NETs, histones (citH3), and coagulant factors (FV and FX). Neutrophil elastase can co-localize with tissue factor pathway inhibitor (TFPI) on NETs and facilitates TFPI degradation, resulting in an activated coagulation system. The presence of citH3 on NETs is known to induce platelet aggregation via involvement of TLR2 and TLR4. Cathepsin G can activate protease activated receptor (PAR)-4, resulting in further platelet activation. As more blood cells become further incorporated and recruited into growing thrombi, fibrin scaffolds are formed. Under homeostatic conditions, neutrophils generally produce annexin A1 (AnxA1), which counteracts proinflammatory responses and enables resolution. However, in SCD, AnxA1 levels are low. Dotted lines separate the different phases of SCD vascular immunopathology. 
Neutrophils form an important link bridging inflammation and thrombosis, a phenomenon referred to as thromboinflammation, by their ability to produce proinflammatory/prothrombotic mediators, such as neutrophil serine proteases (eg, cathepsin $\mathrm{G}$ and neutrophil elastase) ${ }^{34}$ and chromatin structures called NETs ${ }^{35}$ on activation. Neutrophil serine proteases can regulate proinflammatory/ prothrombotic responses by interacting with platelets, coagulation factors, ${ }^{34}$ and binding with formyl peptide receptors on neutrophils and monocytes. ${ }^{36}$ In addition, NETs are stimulated by pathogens as well as other stimuli (eg, activated platelets ${ }^{37}$ and heme), ${ }^{16}$ especially under chronic inflammatory phenotypes, such as SCD. Furthermore, a variety of studies have found that NETs can capture platelets and RBCs, forming a complex network, which can lead to VOCs. ${ }^{35}$ Activated endothelial cells induce NET release and kill endothelial cells. ${ }^{38}$ Our preclinical results indicate that NETs act as prothrombotic scaffolds and play a major role in cerebral thrombus formation (J.A., F.N.E.G., unpublished data) ${ }^{39}$ (Figure 1).

Formyl peptide receptors are G-protein-coupled receptors expressed mainly by myeloid cells with proinflammatory as well as anti-inflammatory responses, depending on the disease state and ligand interaction. ${ }^{40}$ Annexin A1 is an endogenous anti-inflammatory/proresolving mediator secreted mainly by neutrophils whose levels are known to be low in patients with SCD. ${ }^{41}$ Annexin A1 is known to be protective in I/RI-based vascular inflammation and may have a role in the management of SCD. ${ }^{42}$

\section{Platelets}

Platelets have an essential role in the pathogenesis of SCD by interacting constantly with RBCs, neutrophils, and monocytes. ${ }^{4}$ Activated platelets piggyback on neutrophils, inducing neutrophil polarization and triggering direct migration of neutrophils to initiate inflammation in a P-selectin-dependent manner. ${ }^{43}$ Platelet function is significantly altered in SCD and is associated with an abnormal phenotype marked by surface-mobilized, activation-dependent antigens and microparticle formation. ${ }^{44}$ Increased circulating activated platelets have been observed in patients with $\mathrm{SCD}^{45}$ along with increased circulating levels of platelet products, such as thrombospondin and increased expression of P-selectin (which mediates the adhesion of erythrocytes and leukocytes in venules of sickle cell $\left(\beta^{S}\right)$ transgenic mice) ${ }^{43,46}$ In addition, evidence exists in patients with SCD of ongoing generation of thrombin, ${ }^{47}$ which may mediate the platelet activation observed in this disease.

\section{Cerebral I/RI}

Clinical hallmarks of SCD, which include hemolytic anemia, VOC, and vascular endothelial dysfunction, all contribute to the increased risk of cerebral ischemic injury in $\mathrm{SCD},{ }^{3}$ which constitutes $54 \%$ of all cerebrovascular accidents ${ }^{48}$ and is one of the most devastating complications of SCD. The risk of overt stroke for children with SCD is $>333$ times higher than that for the general population, and this burden continues well into adulthood, with approximately $11 \%$ of patients with SCD having clinically apparent strokes before the age of 20 years, increasing to $24 \%$ by the age of 45 years. ${ }^{48,49}$ These figures are likely to be far greater because of the increased incidence of SCIs, which, although quantifiable by magnetic resonance imaging (MRI), produce no or subtle transient focal neurologic signs. ${ }^{50}$ As a consequence of overt stroke or SCIs, patients with SCD can have a global neurocognitive impairment as well as sensory and motor deficits. ${ }^{51}$ Thus, the combined frequency and overall burden of these ischemic events in the brain of patients with SCD not only are likely to be underestimated but also still remain poorly understood.

The pathophysiology of stroke induction is similar to most other complications of SCD. The deformed and sticky RBCs adhere to the surrounding endothelium in cerebral vessels, ${ }^{52}$ resulting in endothelial cell damage and I/RI. These events are followed by von Willebrand factor release, platelet aggregation, and innate and adaptive immune system activation as described previously. ${ }^{53,54}$ The whole process causes further hypoxia and acidosis and consequently further sickling. Prolonged exposure to ischemia also causes irreversible and fatal consequences to resident neurons, including cellular changes, such as nuclear fragmentation, chromatin condensation, and cell body shrinkage. ${ }^{55}$ Bloodborne cells, such as $\mathrm{T}$ lymphocytes, which are known to accumulate in the postischemic brain within 24 hours, also play an important role in the detrimental effects associated with cerebral I/RI in SCD by modulating the recruitment of adherent leukocytes and platelets. ${ }^{56}$ Furthermore, increases in cerebral blood flow, as measured by high transcranial Doppler velocity, and platelet-derived growth factor-mediated cerebral arterial remodeling also contribute to the overall increased risk of cerebrovascular diseases in SCD. ${ }^{57}$

\section{Remote Organ Injury in SCD}

SCD mounts a widespread systemic inflammatory response attributable to chronic leukocyte and endothelial cell activation, multiple elevated inflammatory mediators (eg, IL-6, tumor necrosis factor- $\alpha$, IL-1 $\beta$ ), ${ }^{10}$ and acutephase reactants (eg, C-reactive peptide, secretory phospholipase $\mathrm{A}_{2}$, and granulocyte colony-stimulating factor). This persistent, unresolved inflammation may culminate in remote organ injury or multiorgan dysfunction syndrome ${ }^{58}$ by promoting neutrophil activation, inducing generalized leukocyte and endothelial adhesion molecule expression, and enhancing the opportunities for leukocyte-endothelial cell interactions. ${ }^{10,59}$ The same widespread inflammatory 


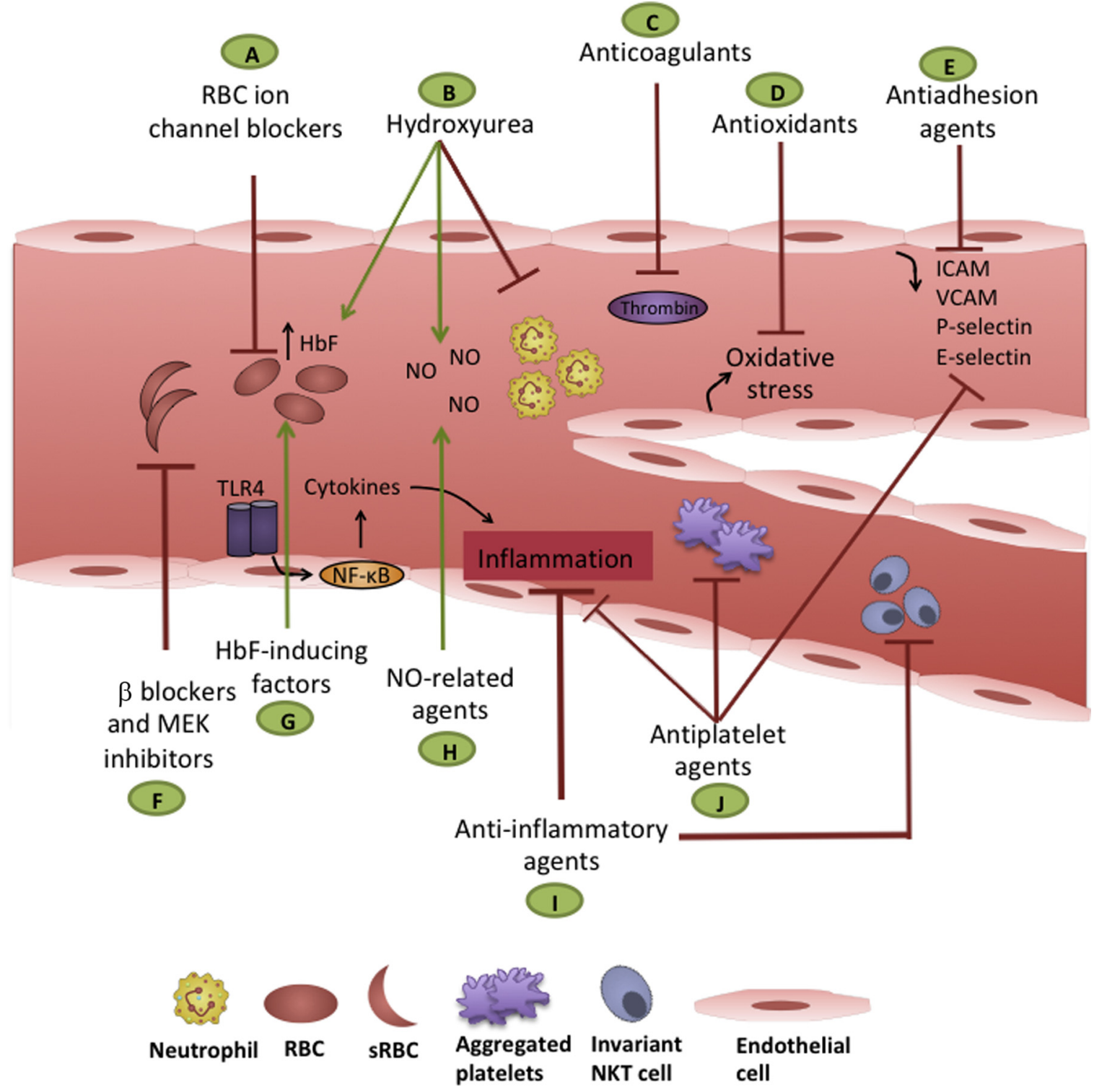

Figure 2 Schematic depiction of potential therapeutic targets in sickle cell disease (SCD). The depicted targets have been tested as potential therapeutics for ischemia reperfusion injury (I/RI) and its associated symptoms in SCD. A: Red blood cell (RBC) ion channel blockers (Gardos channel blockers, eg, senicapoc) can preserve sickle RBC (sRBC) hydration and improve survival. B: Hydroxyurea acts by inducing fetal hemoglobin (HbF), donating nitric oxide (NO), and decreasing circulating leukocytes and reticulocytes. C: Anticoagulants, such as direct thrombin inhibitors (eg, dabigatran), will reduce thromboinflammation. D: Antioxidants, such as arginine and L-glutamine, reduce the oxidant stress by improving NAD redox potential. E: Antiadhesion agents prevent cellular rolling and adhesion to the endothelium by decreasing the expression of intercellular adhesion molecule (ICAM), vascular cell adhesion molecule (VCAM), E-selectin, and P-selectin (eg, rivipansel and crizanlizumab). F: $\beta$-blockers and mitogen-activated protein/extracellular signal-regulated kinase (MEK) inhibitors reduce SRBC adhesion to the vascular endothelium and can be used for management of acute vaso-occlusive episodes. G: $\mathrm{HbF}$-inducing factors, such as hydroxyurea, and other agents (eg, decitabine, pomalidomide, butyrates) can increase HbF, lessen the HbS load, and decrease the rate of hemolysis. H: Nitric oxide-related agents may act by vasodilation and inhibition of vascular remodeling. I: Anti-inflammatory agents include antiadhesion agents, adenosine A2A receptors, and $\beta_{2}$-adrenergic pathways, which will help manage SCD by reducing overall inflammation and ischemia-reperfusion-related injury. J: Antiplatelet agents may reduce inflammatory tone, decrease platelet activation and aggregation, and reduce expression of adhesion molecules and selectins. Green arrows indicate activation/stimulation; brown lines, inhibition.

response has also been seen in sickle transgenic mice with leukocytosis, increased oxidant generation, ${ }^{60}$ and heightened interactions between leukocytes and endothelial cells. $^{30}$

I/RI is a central pathophysiologic process that drives remote organ injury in SCD, with the lungs being the most vulnerable organs. ${ }^{24}$ Numerous studies have established that remote organ injury can also occur in other organs (eg, gut, liver, skeletal muscle, and heart). ${ }^{24}$ Xanthine oxidase, which accumulates throughout the initial ischemic period, results in the generation of massive amounts of ROS, endothelial dysfunction, and xanthine oxidase-derived oxidant-induced release of chemotactic factors, which promote leukocyte recruitment. The postischemic blood also causes priming 
Table 1 Emerging Ischemia and Reperfusion Therapeutics in SCD

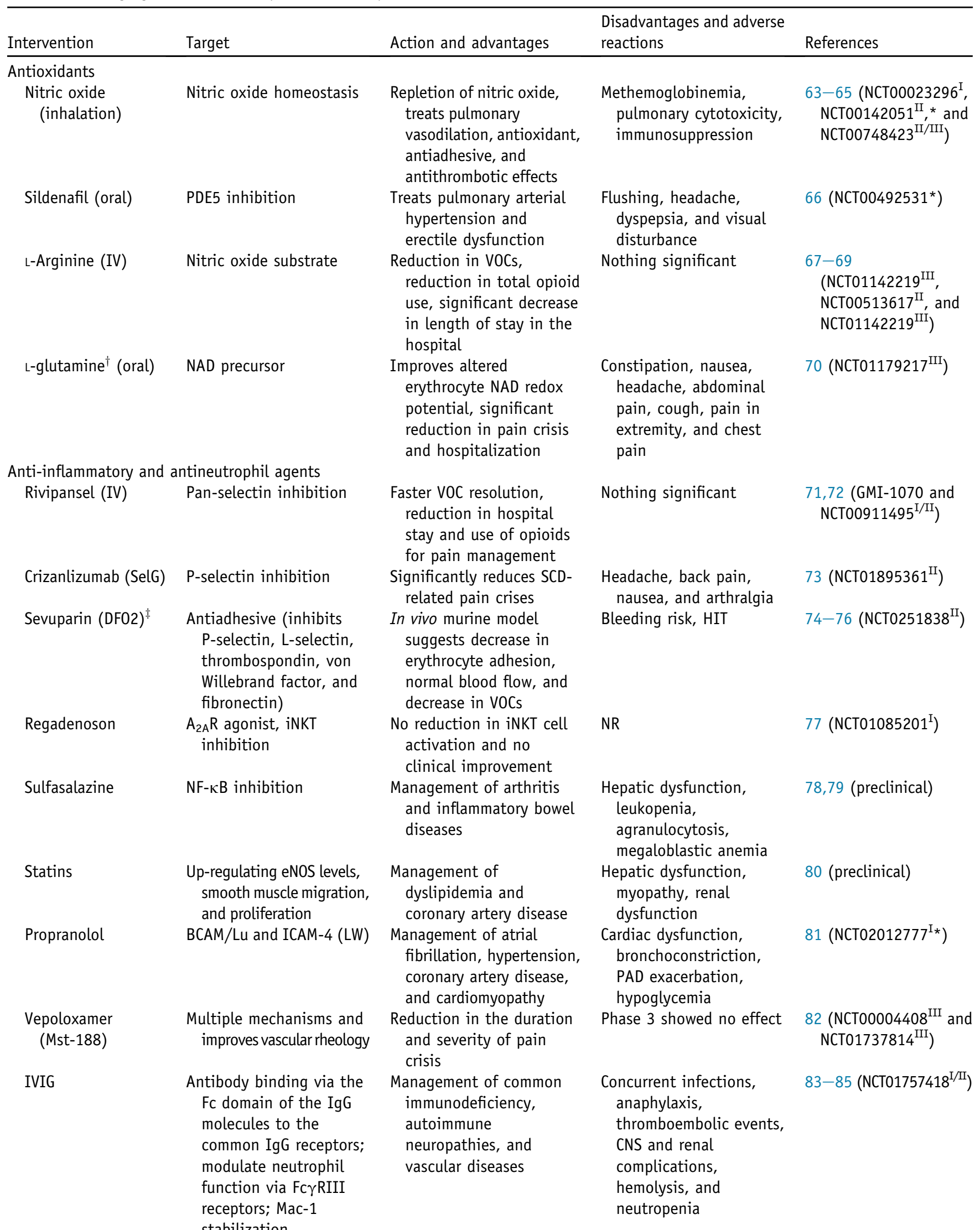


Table 1 (continued)

\begin{tabular}{|c|c|c|c|c|}
\hline Intervention & Target & Action and advantages & $\begin{array}{l}\text { Disadvantages and adverse } \\
\text { reactions }\end{array}$ & References \\
\hline \multicolumn{5}{|c|}{ Antiplatelet and anticoagulant therapy } \\
\hline Dabigatran & Direct thrombin inhibitor & $\begin{array}{l}\text { Reduced neutrophil } \\
\text { infiltrates in the } \\
\text { pulmonary tissue }\end{array}$ & $\begin{array}{l}\text { Bruising and minor } \\
\text { bleeding }\end{array}$ & 86 \\
\hline Rivaroxaban & Factor $\mathrm{X}$ inhibitor & $\begin{array}{l}\text { Reduce inflammation, } \\
\text { coagulation, and } \\
\text { endothelial cell } \\
\text { activation, oral drug }\end{array}$ & Bleeding abnormalities & 87 (NCT02072668 $8^{\mathrm{II}}$ ) \\
\hline Prasugrel & P2Y12 inhibition & $\begin{array}{l}\text { Reduce platelet activation } \\
\text { and vaso-occlusive pain, } \\
\text { oral drug; well tolerated } \\
\text { and safe }\end{array}$ & $\begin{array}{l}\text { Phase } 3 \text { showed } \\
\text { nonsignificant } \\
\text { reduction in vaso- } \\
\text { occlusive crises among } \\
\text { children with SCD, } \\
\text { increased bleeding risk }\end{array}$ & 88,89 (NCT01794000) \\
\hline
\end{tabular}

*Terminated.

†US Food and Drug Administration approved.

${ }_{\ddagger}^{\ddagger}$ US Food and Drug Administration approved for a rare pediatric disease designation.

$A_{2 A} R$, adenosine A2A receptor; BCAM/Lu, basal cell adhesion molecule and its isoform Lutheran; CNS, central nervous system; eNOS, endothelial nitric oxide synthase; HIT, heparin induced thrombocytopenia; ICAM-4 (LW), I] intercellular adhesion molecule-4 (Landsteiner-Wiener blood); iNKT, invariant natural killer T; IV, intravenous; IVIG, intravenous immunoglobulin; NR, not recorded; PAD, peripheral artery disease; PDE5, phosphodiesterase type 5 inhibitor; SCD, sickle cell disease; VOC, vaso-occlusive crisis.

and recruitment of neutrophils and complement system to remote tissues. ${ }^{23}$

\section{Therapeutic Strategies for Treating I/RI in SCD}

Despite the discovered molecular nature of SCD, huge disparities exist in developing therapies compared with other diseases, mainly because of the limited investment from the pharmaceutical industry and marginal clinical trials. Hydroxyurea, exchange blood transfusions, and the recently approved L-glutamine are currently the only available disease-modifying therapies. ${ }^{3}$ Most of the focus of the treatment to date has been on the symptomatic and preventive aspects of the disease, including antibiotic prophylaxis, routine immunizations, and management of acute painful crisis with appropriate analgesia and hydration. ${ }^{3}$ Successful stem cell transplantation can cure sickle cell anemia, but it is only performed in a few patients (with variable outcomes) because of its high cost, lack of suitable donors, widespread complications, and lack of availability in every center. ${ }^{61}$ Other recent strategies lie in the field of gene editing. Using CRISPR-Cas9 gene editing, scientists have been able to repair the defective genes in cells taken from patients with SCD by up to $25 \%$, although less success was observed when the edited cells were tested in vivo. ${ }^{62}$ However, this idea of correcting the gene is far from being a readily available and acceptable clinical strategy for the treatment (and cure) of SCD.

The main focus of SCD management has been on the associated pain, which has given good short-term benefits without a substantial long-term therapeutic impact. Understanding the complex pathophysiologic mechanisms of SCD has led to multiple potential targets in the I/RI cascade, which may have long-term beneficial outcomes (Figure 2 and Table $1^{63-89}$ ). Some of these targets and strategies are discussed here.

\section{AntiSickling Agents}

Antisickling is the most common disease-modifying strategy in SCD. These agents increase fetal hemoglobin (HbF) levels, lessen the HbS load, and decrease the rate of hemolysis. ${ }^{3}$ The most common antiswitching agent used is hydroxyurea; other agents that result in $\mathrm{HbF}$ induction have not proven to be as efficacious. Hydroxyurea was approved by the US Food and Drug Administration (FDA) for use in SCD in February 1998 and is believed to be acting via multiple pathways to induce $\mathrm{HbF},{ }^{90}$ although the actual mechanism of action is still under debate. However, it is known that hydroxyurea acts as a nitric oxide donor, ${ }^{91}$ stabilizing erythrocyte structure and decreasing circulating leukocytes and reticulocytes, all of which mitigate I/RI in SCD. ${ }^{92}$

Multiple trials have evaluated the role of hydroxyurea in SCD in both adults and children, demonstrating reductions in severity and frequency of VOC. ${ }^{93,94}$ Furthermore, hydroxyurea significantly decreases adhesion molecules, such as VCAM-1, and reduces the adhesion of RBCs to the endothelium. ${ }^{95}$ There are many trials in progress with different end points [eg, $\mathrm{HbF}$ response, acute complications, maximum tolerated dose, and percentage of dense RBCs 
(NCT01960413, NCT02225132, NCT02042222)]. Of interest, other HbF-inducing agents (eg, decitabine, pomalidomide, butyrates ACY-957, Pracinostat, KLF1-ASOs, valproic acid, and trichostatin) are in preclinical or clinical testing or in development. ${ }^{3}$

\section{Anti-Inflammatory Agents and Antineutrophil Agents}

Many aspects of SCD, including multifocal microvascular occlusions and chronic inflammation, are consistent with I/RI. Targeting mechanisms of the inflammatory cascade, such as adhesive interactions between cellular components (eg, leukocytes, platelets, RBCs, and the endothelium), are of great interest as therapeutic targets. ${ }^{10}$ Table 1 provides a comprehensive list of anti-inflammatory and antioxidant agents that have been tried in various studies. Some drugs and receptors or pathways of particular interest are as follows.

\section{Selectin Inhibitors}

Selectins mediate cellular rolling and adhesion to the endothelium. In particular, endothelial cells, as well as plateletderived P-selectin, have a key role in the pathogenesis of VOCs, and P-selectin mediates adhesion of SS RBCs to vessels and assists in the formation of neutrophil-platelet aggregates. ${ }^{73}$ In vivo studies have found that inhibition of adhesion molecules reduces VOCs significantly, ${ }^{30,73,96}$ with the most commonly studied antiadhesive agent, the pan-selectin inhibitor GMI-1070 (rivipansel), reducing VOCs and disease severity in vivo. ${ }^{96}$ A recently completed phase $1 / 2$ study found high tolerability of GMI-1070 and suggested increased blood flow in a subset of patients (NCT00911495). ${ }^{71}$ Telen et $\mathrm{al}^{72}$ completed a phase 2 study, which revealed clinically relevant reductions in time of resolution of VOCs, length of stay in the hospital, and opioid dose needed after GMI 1070 administration (NCT01119833).

Several studies have found positive effects in specifically blocking P-selectin. In a recent double-blind, randomized, placebo-controlled phase 2 trial, patients receiving a high dose of P-selectin inhibitor crizanlizumab (SelG1) had a significantly lower rate of sickle cell-related pain crises than placebo. ${ }^{73}$ Sevuparin (low-molecular-weight heparin) has low anticoagulant activity but is a potent P-selectin blocker, inhibiting HbSS RBC adhesion to the endothelium and reducing tumor necrosis factor-induced VOCs. ${ }^{76}$ Sevuparin is currently undergoing a phase II trial (NCT0251838) for the management of acute VOCs.

\section{Adenosine A2A Receptors and $\beta_{2}$-Adrenergic Pathway}

The $\beta_{2}$-adrenergic system also plays a significant role in adhesion pathways via activation of basal cell adhesion molecule and its isoform Lutheran and intercellular adhesion molecule-4 (Landsteiner-Wiener blood). ${ }^{81}$ Epinephrine elevates cAMP and increases adhesion in a B-adrenergic and protein kinase A-dependent manner (NCT02012777). ${ }^{81}$ Invariant natural killer $\mathrm{T}$ (iNKT) cells become activated and increase in number during painful VOCs in SCD. Concomitantly, there is an increase in NF- $\kappa \mathrm{B}$ phosphorylation, an increase in adenosine $\mathrm{A} 2 \mathrm{~A}$ receptor expression, and an increase in interferon- $\gamma$ levels, all instigating inflammation during VOCs. Adenosine A2A receptor agonists can decrease the iNKT cell activation and may limit painful crisis in SCD. In a recent phase 1 study, regadenoson, an adenosine $\mathrm{A} 2 \mathrm{~A}$ receptor agonist, reduced the activation of iNKT cells without causing any toxic effects. ${ }^{77}$ However, the phase 2 trial did not find any improvement in the clinical outcomes and nonsignificant reduction of iNKT cell activation between regadenoson treatment and placebo groups in SCD. ${ }^{97}$ Sulfasalazine is a potent and specific inhibitor of NF- $\mathrm{KB}$ activation ${ }^{78}$ and modulates endothelial function and significantly ameliorates secondary inflammatory damage (by reducing the expression of intercellular adhesion molecule, E-selectin, and VCAM, thus decreasing leukocyte recruitment) caused by SCD in multiple animal and human studies. ${ }^{79,98,99}$

\section{Targeting Neutrophils by IVIGs}

The working mechanism of immunomodulation by intravenous immunoglobulins (IVIGs) is still not completely understood, but research in the last decade has primarily focused on classic antibody binding via the Fc-domain of the IgG molecules to the common IgG receptors. Multiple studies have found a role of IVIG in modulating neutrophil activation, decreasing RBC-neutrophil interactions, inhibiting adhesion, and increasing their flow and survival. ${ }^{83}$ These effects are mainly mediated via neutrophil specific Fc $\gamma$ RIII receptors ${ }^{84}$ and Mac-1. ${ }^{85}$ An ongoing phase $1 / 2$ trial (NCT01757418) is currently recruiting patients to assess the effects of IVIG on sickle cell pain crisis. In contrast to GMI-1070, low-dose IVIG at 200 to $400 \mathrm{mg} / \mathrm{kg}$ may have a better overall efficacy because of less of an increase in white blood cell and neutrophil counts, resulting in an increased effect on RBC capture. ${ }^{85}$

\section{Antiplatelet and Anticoagulants}

Although drugs that target the generation (eg, warfarin) or activity (eg, heparin) of thrombin have been tested for prevention of sickle cell crises, high oral doses proved not to be beneficial because of major bleeding complications. ${ }^{100}$ However, lower doses, which may have greater benefit, have not yet been evaluated in randomized trials in patients with SCD. Nonetheless, thrombin remains a viable therapeutic target for prevention of the enhanced thrombosis in $\mathrm{SCD} .{ }^{86}$ In a preclinical study, a 10-day treatment of sickle mice with dabigatran (a direct thrombin inhibitor) resulted in reduced neutrophil infiltrates in the pulmonary tissue ${ }^{86}$ Prasugrel, an oral P2Y12 receptor inhibitor that prevents ADP-dependent platelet activation, has been also tested in various preclinical and clinical 
trials for determining effects on vaso-occlusive events; so far, the results have failed to prove any substantial reduction. ${ }^{88,89}$

\section{Oxidative and Nitrosative Targets}

Oxidative and nitrosative stress and nitric oxide depletion play a pivotal role in the pathophysiologic mechanisms of SCD. Nitric oxide inhibits leukocyte adhesion and platelet adhesion and activation, thus blunting hemolysis and thromboinflammation associated with SCD. ${ }^{10,101}$ Several agents that target different aspects of oxidant and nitric oxide biology have been used to modify SCD and reduce VOC events (Table 1). Some of the particular interest are as follows.

\section{Nitrite Therapy}

Initial studies in animals, as well as humans, had some promise with inhaled nitric oxide therapy. de Franceschi et $\mathrm{al}^{63}$ subjected transgenic mice with SCD to hypoxia and reoxygenation, coupled with inhalation of nitric oxide, and found that this prevented histopathologic lung damage, attenuated inflammatory responses, modulated genes involved in I/RI, modulated vascular rheology, and attenuated RBC dehydration. However, in adults with SCD and mild to moderate ACS, nitric oxide therapy failed to show any reduction in treatment, suggesting that nitric oxide therapy is complex and requires further understanding. ${ }^{64}$ The failure of inhaled nitric oxide may be because it mainly targets the lungs and was used under acute care settings, which may have been insufficient for I/RI affected tissues ${ }^{101}$ with less systemic action.

\section{Phosphodiesterase and Endothelin Receptor Inhibition}

SCD is associated with a significant oxidant stress, which is attributable to lower redox potential attributed mainly to arginase release from intravascular hemolysis and endothelial production under a proinflammatory state. ${ }^{67}$ The resulting deficit in arginine is known to contribute to VOC and early mortality. ${ }^{67}$ Preliminary clinical studies with arginine therapy, including a phase 2 trial, found efficacy in managing acute $\mathrm{VOCs}^{67}$ and other complications, such as leg ulcers ${ }^{68}$ and $\mathrm{PH} .{ }^{69}$

L-glutamine is a precursor of NAD and prevents oxidant damage to RBCs by improving the NAD redox potential. ${ }^{70}$ A recent phase 3 trial (NCT01179217) found that it provides clinical benefit over placebo by reducing the frequency of painful crisis and hospitalization. ${ }^{102}$ L-glutamine was recently approved by the FDA to reduce acute complications of SCD in adult and pediatric patients $(\geq 5$ years old). ${ }^{103}$ In addition, a multicenter randomized clinical trial of sildenafil for PH in patients with SCD (termed the walkPHaSST) was stopped because of serious adverse effects in the treatment group. ${ }^{66}$ Results were also inconclusive when endothelin receptor blockade was used (Asset-1 and -2, with bosentan) as a potential therapy for $\mathrm{PH} .{ }^{104}$

\section{Conclusions}

The role of I/RI in the pathophysiology of SCD is complex and needs further understanding. Reperfusion injury attributable to ROS production and cellular activation plays a major role in SCD and should set the stage for more robust and durable preclinical and clinical research, ultimately paving the way for new disease-modifying agents. In addition, SCD is a thromboinflammatory state that contributes to chronic inflammation and I/RI. Targeting various thrombosis and coagulation mechanisms and pathways may also be another viable therapeutic strategy for drug discovery programs. The recent FDA approval of L-glutamine, promising results with crizanlizumab, and the continued success of hydroxyurea in both the pediatric and adult populations have given more impetus to the study of the various checkpoints in the I/RI-based pathophysiology in SCD. In summary, because SCD is a systemic and widespread disease that involves a panoply of cellular mediators and pathways, a more individualized multitargeted therapeutic approach might be the future for SCD medicine.

\section{Acknowledgment}

We thank Youmna Moufarrej (Louisiana State University Medical School) for her help with the illustrations.

\section{References}

1. Bunn HF: Pathogenesis and treatment of sickle cell disease. N Engl J Med 1997, 337:762-769

2. Luzzatto L: Sickle cell anaemia and malaria. Mediterr J Hematol Infect Dis 2012, 4:e2012065

3. Ansari J, Moufarrej YE, Pawlinski R, Gavins FNE: Sickle cell disease: a malady beyond a hemoglobin defect in cerebrovascular disease. Expert Rev Hematol 2018, 11:45-55

4. Zhang D, Xu C, Manwani D, Frenette PS: Neutrophils, platelets, and inflammatory pathways, at the nexus of sickle cell disease pathophysiology. Blood 2016, 127:801-809

5. Kato GJ, Piel FB, Reid CD, Gaston MH, Ohene-Frempong $\mathrm{K}$, Krishnamurti L, Smith WR, Panepinto JA, Weatherall DJ, Costa FF, Vichinsky EP: Sickle cell disease. Nat Rev Dis Primers 2018, 4:18010

6. Sabina RL, Wandersee NJ, Hillery CA: Ca2+-CaM activation of AMP deaminase contributes to adenine nucleotide dysregulation and phosphatidylserine externalization in human sickle erythrocytes. Br J Haematol 2009, 144:434-445

7. Vekilov PG: Sickle-cell haemoglobin polymerization: is it the primary pathogenic event of sickle-cell anaemia? Br J Haematol 2007, 139:173-184

8. Connes P, Alexy T, Detterich J, Romana M, Hardy-Dessources MD, Ballas SK: The role of blood rheology in sickle cell disease. Blood Rev 2016, 30:111-118

9. Kaul DK, Finnegan E, Barabino GA: Sickle red cell-endothelium interactions. Microcirculation 2009, 16:97-111

10. Hebbel RP: Ischemia-reperfusion injury in sickle cell anemia: relationship to acute chest syndrome, endothelial dysfunction, arterial vasculopathy, and inflammatory pain. Hematol Oncol Clin North Am 2014, 28:181-198

11. Schaer DJ, Buehler PW, Alayash AI, Belcher JD, Vercellotti GM: Hemolysis and free hemoglobin revisited: exploring hemoglobin and 
hemin scavengers as a novel class of therapeutic proteins. Blood 2013, 121:1276-1284

12. Camus SM, De Moraes JA, Bonnin P, Abbyad P, Le Jeune S, Lionnet F, Loufrani L, Grimaud L, Lambry JC, Charue D, Kiger L, Renard JM, Larroque C, Le Clésiau H, Tedgui A, Bruneval P, BarjaFidalgo C, Alexandrou A, Tharaux PL, Boulanger CM, BlancBrude OP: Circulating cell membrane microparticles transfer heme to endothelial cells and trigger vasoocclusions in sickle cell disease. Blood 2015, 125:3805-3814

13. Wang X, Mendelsohn L, Rogers H, Leitman S, Raghavachari N, Yang Y, Yau YY, Tallack M, Perkins A, Taylor JG, Noguchi CT, Kato GJ: Heme-bound iron activates placenta growth factor in erythroid cells via erythroid Krüppel-like factor. Blood 2014, 124: 946-954

14. Belcher JD, Chen C, Nguyen J, Milbauer L, Abdulla F, Alayash AI, Smith A, Nath KA, Hebbel RP, Vercellotti GM: Heme triggers TLR4 signaling leading to endothelial cell activation and vaso-occlusion in murine sickle cell disease. Blood 2014, 123:377-390

15. Dutra FF, Bozza MT: Heme on innate immunity and inflammation. Front Pharmacol 2014, 5:115

16. Chen G, Zhang D, Fuchs TA, Manwani D, Wagner DD, Frenette PS: Heme-induced neutrophil extracellular traps contribute to the pathogenesis of sickle cell disease. Blood 2014, 123: $3818-3827$

17. Fernandez PL, Dutra FF, Alves L, Figueiredo RT, Mourao-Sa D, Fortes GB, Bergstrand S, Lonn D, Cevallos RR, Pereira RM, Lopes UG, Travassos LH, Paiva CN, Bozza MT: Heme amplifies the innate immune response to microbial molecules through spleen tyrosine kinase (Syk)-dependent reactive oxygen species generation. J Biol Chem 2010, 285:32844-32851

18. Hebbel RP, Osarogiagbon R, Kaul D: The endothelial biology of sickle cell disease: inflammation and a chronic vasculopathy. Microcirculation 2004, 11:129-151

19. Cines DB, Pollak ES, Buck CA, Loscalzo J, Zimmerman GA, McEver RP, Pober JS, Wick TM, Konkle BA, Schwartz BS, Barnathan ES, McCrae KR, Hug BA, Schmidt AM, Stern DM: Endothelial cells in physiology and in the pathophysiology of vascular disorders. Blood 1998, 91:3527-3561

20. Shet AS, Aras O, Gupta K, Hass MJ, Rausch DJ, Saba N, Koopmeiners L, Key NS, Hebbel RP: Sickle blood contains tissue factor-positive microparticles derived from endothelial cells and monocytes. Blood 2003, 102:2678-2683

21. Lopes FC, Traina F, Almeida CB, Leonardo FC, FrancoPenteado CF, Garrido VT, Colella MP, Soares R, Olalla-Saad ST, Costa FF, Conran N: Key endothelial cell angiogenic mechanisms are stimulated by the circulating milieu in sickle cell disease and attenuated by hydroxyurea. Haematologica 2015, 100:730-739

22. Eltzschig HK, Eckle T: Ischemia and reperfusion-from mechanism to translation. Nat Med 2011, 17:1391-1401

23. Carden DL, Granger DN: Pathophysiology of ischaemia-reperfusion injury. J Pathol 2000, 190:255-266

24. Kalogeris T, Baines CP, Krenz M, Korthuis RJ: Cell biology of ischemia/reperfusion injury. Int Rev Cell Mol Biol 2012, 298: 229-317

25. Sanada S, Komuro I, Kitakaze M: Pathophysiology of myocardial reperfusion injury: preconditioning, postconditioning, and translational aspects of protective measures. Am J Physiol Heart Circ Physiol 2011, 301:H1723-H1741

26. Arumugam TV, Shiels IA, Woodruff TM, Granger DN, Taylor SM: The role of the complement system in ischemia-reperfusion injury. Shock 2004, 21:401-409

27. Maiocchi S, Alwis I, Wu MCL, Yuan Y, Jackson SP: Thromboinflammatory functions of platelets in ischemia-reperfusion injury and its dysregulation in diabetes. Semin Thromb Hemost 2018, 44: $102-113$

28. Rao J, Lu L, Zhai Y: T cells in organ ischemia reperfusion injury. Curr Opin Organ Transplant 2014, 19:115-120
29. Lefer AM, Tsao PS, Lefer DJ, Ma XL: Role of endothelial dysfunction in the pathogenesis of reperfusion injury after myocardial ischemia. FASEB J 1991, 5:2029-2034

30. Kaul DK, Hebbel RP: Hypoxia/reoxygenation causes inflammatory response in transgenic sickle mice but not in normal mice. J Clin Invest 2000, 106:411-420

31. Deniset JF, Kubes P: Recent advances in understanding neutrophils. F1000Res 2016, 5:2912

32. Zhang D, Chen G, Manwani D, Mortha A, Xu C, Faith JJ, Burk RD, Kunisaki Y, Jang JE, Scheiermann C, Merad M, Frenette PS: Neutrophil ageing is regulated by the microbiome. Nature 2015, 525: $528-532$

33. Cober MP, Phelps SJ: Penicillin prophylaxis in children with sickle cell disease. J Pediatr Pharmacol Ther 2010, 15:152-159

34. Massberg S, Grahl L, von Bruehl ML, Manukyan D, Pfeiler S, Goosmann C, Brinkmann V, Lorenz M, Bidzhekov $\mathrm{K}$, Khandagale AB, Konrad I, Kennerknecht E, Reges K, Holdenrieder S, Braun S, Reinhardt C, Spannagl M, Preissner KT, Engelmann B: Reciprocal coupling of coagulation and innate immunity via neutrophil serine proteases. Nat Med 2010, 16:887-896

35. Fuchs TA, Brill A, Duerschmied D, Schatzberg D, Monestier M Myers DD, Wrobleski SK, Wakefield TW, Hartwig JH, Wagner DD: Extracellular DNA traps promote thrombosis. Proc Natl Acad Sci U S A 2010, 107:15880-15885

36. Woloszynek JC, Hu Y, Pham CT: Cathepsin G-regulated release of formyl peptide receptor agonists modulate neutrophil effector functions. J Biol Chem 2012, 287:34101-34109

37. Brinkmann V, Zychlinsky A: Beneficial suicide: why neutrophils die to make NETs. Nat Rev Microbiol 2007, 5:577-582

38. Gupta AK, Joshi MB, Philippova M, Erne P, Hasler P, Hahn S, Resink TJ: Activated endothelial cells induce neutrophil extracellular traps and are susceptible to NETosis-mediated cell death. FEBS Lett 2010, 584:3193-3197

39. Gavins FN, Russell J, Senchenkova EL, De Almeida Paula L, Damazo AS, Esmon CT, Kirchhofer D, Hebbel RP, Granger DN: Mechanisms of enhanced thrombus formation in cerebral microvessels of mice expressing hemoglobin-S. Blood 2011, 117: $4125-4133$

40. Gavins FN: Are formyl peptide receptors novel targets for therapeutic intervention in ischaemia-reperfusion injury? Trends Pharmacol Sci 2010, 31:266-276

41. Torres LS, Okumura JV, Silva DG, Mimura KK, Belini-Junior E, Oliveira RG, Lobo CL, Oliani SM, Bonini-Domingos CR: Inflammation in sickle cell disease: differential and down-expressed plasma levels of annexin A1 protein. PLoS One 2016, 11:e0165833

42. Ansari J, Kaur G, Gavins FNE: Therapeutic potential of annexin A1 in ischemia reperfusion injury. Int J Mol Sci 2018, 19

43. Polanowska-Grabowska R, Wallace K, Field JJ, Chen L, Marshall MA, Figler R, Gear AR, Linden J: P-selectin-mediated platelet-neutrophil aggregate formation activates neutrophils in mouse and human sickle cell disease. Arterioscler Thromb Vasc Biol 2010, 30:2392-2399

44. Garnier Y, Ferdinand S, Etienne-Julan M, Elana G, Petras M, Doumdo L, Tressieres B, Lalanne-Mistrih ML, HardyDessources MD, Connes P, Romana M: Differences of microparticle patterns between sickle cell anemia and hemoglobin SC patients. PLoS One 2017, 12:e0177397

45. Proenca-Ferreira R, Brugnerotto AF, Garrido VT, Dominical VM, Vital DM, Ribeiro Mde F, dos Santos ME, Traina F, Olalla-Saad ST, Costa FF, Conran N: Endothelial activation by platelets from sickle cell anemia patients. PLoS One 2014, 9:e89012

46. Novelli EM, Kato GJ, Ragni MV, Zhang Y, Hildesheim ME, Nouraie M, Barge S, Meyer MP, Hassett AC, Gordeuk VR, Gladwin MT, Isenberg JS: Plasma thrombospondin-1 is increased during acute sickle cell vaso-occlusive events and associated with acute chest syndrome, hydroxyurea therapy, and lower hemolytic rates. Am J Hematol 2012, 87:326-330 
47. Whelihan MF, Lim MY, Key NS: Red blood cells and thrombin generation in sickle cell disease. Thromb Res 2014, 133 Suppl 1: S52-S53

48. Ohene-Frempong K, Weiner SJ, Sleeper LA, Miller ST, Embury S, Moohr JW, Wethers DL, Pegelow CH, Gill FM: Cerebrovascular accidents in sickle cell disease: rates and risk factors. Blood 1998, 91 : 288-294

49. Broderick J, Talbot GT, Prenger E, Leach A, Brott T: Stroke in children within a major metropolitan area: the surprising importance of intracerebral hemorrhage. J Child Neurol 1993, 8:250-255

50. Dowling MM, Quinn CT, Rogers ZR, Buchanan GR: Acute silent cerebral infarction in children with sickle cell anemia. Pediatr Blood Cancer 2010, 54:461-464

51. Armstrong FD, Thompson RJ, Wang W, Zimmerman R, Pegelow CH, Miller S, Moser F, Bello J, Hurtig A, Vass K; Neuropsychology Committee of the Cooperative Study of Sickle Cell Disease: Cognitive functioning and brain magnetic resonance imaging in children with sickle cell disease. Pediatrics 1996, 97:864-870

52. Gavins F, Yilmaz G, Granger DN: The evolving paradigm for blood cell-endothelial cell interactions in the cerebral microcirculation. Microcirculation 2007, 14:667-681

53. Boyton R: The role of natural killer $\mathrm{T}$ cells in lung inflammation. J Pathol 2008, 214:276-282

54. Platt OS: Sickle cell anemia as an inflammatory disease. J Clin Invest 2000, 106:337-338

55. Broughton BR, Reutens DC, Sobey CG: Apoptotic mechanisms after cerebral ischemia. Stroke 2009, 40:e331-e339

56. Yilmaz G, Granger DN: Leukocyte recruitment and ischemic brain injury. Neuromolecular Med 2010, 12:193-204

57. Hyacinth HI, Gee BE, Adamkiewicz TV, Adams RJ, Kutlar A, Stiles JK, Hibbert JM: Plasma BDNF and PDGF-AA levels are associated with high TCD velocity and stroke in children with sickle cell anemia. Cytokine 2012, 60:302-308

58. Park SW, Kim M, Brown KM, D’Agati VD, Lee HT: Paneth cellderived interleukin-17A causes multiorgan dysfunction after hepatic ischemia and reperfusion injury. Hepatology 2011, 53:1662-1675

59. Bone RC: Sepsis and coagulation: an important link. Chest 1992, 101:594-596

60. Osarogiagbon UR, Choong S, Belcher JD, Vercellotti GM, Paller MS, Hebbel RP: Reperfusion injury pathophysiology in sickle transgenic mice. Blood 2000, 96:314-320

61. Fitzhugh CD, Abraham AA, Tisdale JF, Hsieh MM: Hematopoietic stem cell transplantation for patients with sickle cell disease: progress and future directions. Hematol Oncol Clin North Am 2014, 28 : $1171-1185$

62. Li C, Ding L, Sun CW, Wu LC, Zhou D, Pawlik KM, KhodadadiJamayran A, Westin E, Goldman FD, Townes TM: Novel HDAd/EBV reprogramming vector and highly efficient Ad/CRISPR-Cas sickle cell disease gene correction. Sci Rep 2016, 6:30422

63. de Franceschi L, Baron A, Scarpa A, Adrie C, Janin A, Barbi S, Kister J, Rouyer-Fessard P, Corrocher R, Leboulch P, Beuzard Y: Inhaled nitric oxide protects transgenic SAD mice from sickle cell disease-specific lung injury induced by hypoxia/reoxygenation. Blood 2003, 102:1087-1096

64. Maitre B, Djibre M, Katsahian S, Habibi A, Stankovic Stojanovic K, Khellaf M, Bourgeon I, Lionnet F, Charles-Nelson A, Brochard L, Lemaire F, Galacteros F, Brun-Buisson C, Fartoukh M, Mekontso Dessap A: Inhaled nitric oxide for acute chest syndrome in adult sickle cell patients: a randomized controlled study. Intensive Care Med 2015, 41:2121-2129

65. Gladwin MT, Kato GJ, Weiner D, Onyekwere OC, Dampier C, Hsu L, Hagar RW, Howard T, Nuss R, Okam MM, Tremonti CK, Berman B, Villella A, Krishnamurti L, Lanzkron S, Castro O, Gordeuk VR, Coles WA, Peters-Lawrence M, Nichols J, Hall MK, Hildesheim M, Blackwelder WC, Baldassarre J, Caella JF, De NI: Nitric oxide for inhalation in the acute treatment of sickle cell pain crisis: a randomized controlled trial. JAMA 2011, 305:893-902
66. Machado RF, Barst RJ, Yovetich NA, Hassell KL, Kato GJ, Gordeuk VR, Gibbs JS, Little JA, Schraufnagel DE, Krishnamurti L, Girgis RE, Morris CR, Rosenzweig EB, Badesch DB, Lanzkron S, Onyekwere O, Castro OL, Sachdev V, Waclawiw MA, Woolson R, Goldsmith JC, Gladwin MT: Patients w-PIa: hospitalization for pain in patients with sickle cell disease treated with sildenafil for elevated TRV and low exercise capacity. Blood 2011, 118:855-864

67. Morris CR, Kuypers FA, Lavrisha L, Ansari M, Sweeters N, Stewart M, Gildengorin G, Neumayr L, Vichinsky EP: A randomized, placebo-controlled trial of arginine therapy for the treatment of children with sickle cell disease hospitalized with vaso-occlusive pain episodes. Haematologica 2013, 98:1375-1382

68. McMahon L, Tamary H, Askin M, Adams-Graves P, Eberhardt RT, Sutton M, Wright EC, Castaneda SA, Faller DV, Perrine SP: A randomized phase II trial of arginine butyrate with standard local therapy in refractory sickle cell leg ulcers. Br J Haematol 2010, 151: $516-524$

69. Morris CR, Morris SM, Hagar W, Van Warmerdam J, Claster S, Kepka-Lenhart D, Machado L, Kuypers FA, Vichinsky EP: Arginine therapy: a new treatment for pulmonary hypertension in sickle cell disease? Am J Respir Crit Care Med 2003, 168:63-69

70. Niihara Y, Zerez CR, Akiyama DS, Tanaka KR: Oral L-glutamine therapy for sickle cell anemia, I: subjective clinical improvement and favorable change in red cell NAD redox potential. Am J Hematol 1998, 58:117-121

71. Wun T, Styles L, DeCastro L, Telen MJ, Kuypers F, Cheung A, Kramer W, Flanner H, Rhee S, Magnani JL, Thackray H: Phase 1 study of the E-selectin inhibitor GMI 1070 in patients with sickle cell anemia. PLoS One 2014, 9:e101301

72. Telen MJ, Wun T, McCavit TL, De Castro LM, Krishnamurti L, Lanzkron S, Hsu LL, Smith WR, Rhee S, Magnani JL, Thackray H: Randomized phase 2 study of GMI-1070 in SCD: reduction in time to resolution of vaso-occlusive events and decreased opioid use. Blood $2015,125: 2656-2664$

73. Ataga KI, Kutlar A, Kanter J, Liles D, Cancado R, Friedrisch J, Guthrie TH, Knight-Madden J, Alvarez OA, Gordeuk VR, Gualandro S, Colella MP, Smith WR, Rollins SA, Stocker JW, Rother RP: Crizanlizumab for the prevention of pain crises in sickle cell disease. N Engl J Med 2017, 376:429-439

74. Embury SH, Matsui NM, Ramanujam S, Mayadas TN, Noguchi CT, Diwan BA, Mohandas N, Cheung AT: The contribution of endothelial cell P-selectin to the microvascular flow of mouse sickle erythrocytes in vivo. Blood 2004, 104:3378-3385

75. Matsui NM, Varki A, Embury SH: Heparin inhibits the flow adhesion of sickle red blood cells to P-selectin. Blood 2002, 100:3790-3796

76. Batchvarova M, Shan S, Zennadi R, Lindgren M, Leitgeb A, Tamsen PS, Telen MJ: Sevuparin reduces adhesion of both sickle red cells and leukocytes to endothelial cells in vitro and inhibits vasoocclusion in vivo. 55th Annual American Society of Hematology Meeting [abstract], December 2013, New Orleans, LA. American Society of Hematology, 2013

77. Field JJ, Lin G, Okam MM, Majerus E, Keefer J, Onyekwere O, Ross A, Campigotto F, Neuberg D, Linden J, Nathan DG: Sickle cell vaso-occlusion causes activation of iNKT cells that is decreased by the adenosine A2A receptor agonist regadenoson. Blood 2013, 121: 3329-3334

78. Wahl C, Liptay S, Adler G, Schmid RM: Sulfasalazine: a potent and specific inhibitor of nuclear factor kappa B. J Clin Invest 1998, 101: $1163-1174$

79. Volin MV, Harlow LA, Woods JM, Campbell PL, Amin MA, Tokuhira M, Koch AE: Treatment with sulfasalazine or sulfapyridine, but not 5-aminosalicyclic acid, inhibits basic fibroblast growth factor-induced endothelial cell chemotaxis. Arthritis Rheum 1999, 42:1927-1935

80. Laufs U, Gertz K, Dirnagl U, Böhm M, Nickenig G, Endres M: Rosuvastatin, a new HMG-CoA reductase inhibitor, upregulates endothelial nitric oxide synthase and protects from ischemic stroke in mice. Brain Res 2002, 942:23-30 
81. De Castro LM, Zennadi R, Jonassaint JC, Batchvarova M, Telen MJ: Effect of propranolol as antiadhesive therapy in sickle cell disease. Clin Transl Sci 2012, 5:437-444

82. Ballas SK, Files B, Luchtman-Jones L, Benjamin L, Swerdlow P, Hilliard L, Coates T, Abboud M, Wojtowicz-Praga S, Grindel JM: Safety of purified poloxamer 188 in sickle cell disease: phase I study of a non-ionic surfactant in the management of acute chest syndrome. Hemoglobin 2004, 28:85-102

83. Chang J, Shi PA, Chiang EY, Frenette PS: Intravenous immunoglobulins reverse acute vaso-occlusive crises in sickle cell mice through rapid inhibition of neutrophil adhesion. Blood 2008, 111: 915-923

84. Jang JE, Hidalgo A, Frenette PS: Intravenous immunoglobulins modulate neutrophil activation and vascular injury through Fc $\gamma$ RIII and SHP-1. Circ Res 2012, 110:1057-1066

85. Manwani D, Chen G, Carullo V, Serban S, Olowokure O, Jang J, Huggins M, Cohen HW, Billett H, Atweh GF, Frenette PS, Shi PA: Single-dose intravenous gammaglobulin can stabilize neutrophil Mac-1 activation in sickle cell pain crisis. Am J Hematol 2015, 90:381-385

86. Sparkenbaugh E, Pawlinski R: Prothrombotic aspects of sickle cell disease. J Thromb Haemost 2017, 15:1307-1316

87. Telen MJ: Beyond hydroxyurea: new and old drugs in the pipeline for sickle cell disease. Blood 2016, 127:810-819

88. Heeney MM, Hoppe CC, Abboud MR, Inusa B, Kanter J, Ogutu B, Brown PB, Heath LE, Jakubowski JA, Zhou C, Zamoryakhin D, Agbenyega T, Colombatti R, Hassab HM, Nduba VN, Oyieko JN, Robitaille N, Segbefia CI, Rees DC; DOVE Investigators: A multinational trial of prasugrel for sickle cell vaso-occlusive events. N Engl J Med 2016, 374:625-635

89. Conran N, Rees DC: Prasugrel hydrochloride for the treatment of sickle cell disease. Expert Opin Investig Drugs 2017, 26:865-872

90. Mabaera R, West RJ, Conine SJ, Macari ER, Boyd CD, Engman CA, Lowrey $\mathrm{CH}$ : A cell stress signaling model of fetal hemoglobin induction: what doesn't kill red blood cells may make them stronger. Exp Hematol 2008, 36:1057-1072

91. Gladwin MT, Shelhamer JH, Ognibene FP, Pease-Fye ME, Nichols JS, Link B, Patel DB, Jankowski MA, Pannell LK, Schechter AN, Rodgers GP: Nitric oxide donor properties of hydroxyurea in patients with sickle cell disease. Br J Haematol 2002, 116:436-444

92. McGann PT, Ware RE: Hydroxyurea for sickle cell anemia: what have we learned and what questions still remain? Curr Opin Hematol 2011, 18:158-165

93. Charache S, Terrin ML, Moore RD, Dover GJ, Barton FB, Eckert SV, McMahon RP, Bonds DR: Effect of hydroxyurea on the frequency of painful crises in sickle cell anemia. Investigators of the Multicenter Study of hydroxyurea in sickle cell anemia. N Engl J Med 1995, 332:1317-1322

94. Wang WC, Ware RE, Miller ST, Iyer RV, Caella JF, Minniti CP, Rana S, Thornburg CD, Rogers ZR, Kalpatthi RV, Barredo JC,
Brown RC, Sarnaik SA, Howard TH, Wynn LW, Kutlar A, Armstrong FD, Files BA, Goldsmith JC, Waclawiw MA, Huang X, Thompson BW, investigators BH: Hydroxycarbamide in very young children with sickle-cell anaemia: a multicentre, randomised, controlled trial (BABY HUG). Lancet 2011, 377:1663-1672

95. Chaar V, Laurance S, Lapoumeroulie C, Cochet S, De Grandis M, Colin Y, Elion J, Le Van Kim C, El Nemer W: Hydroxycarbamide decreases sickle reticulocyte adhesion to resting endothelium by inhibiting endothelial lutheran/basal cell adhesion molecule (Lu/BCAM) through phosphodiesterase 4A activation. J Biol Chem 2014, 289:11512-11521

96. Chang J, Patton JT, Sarkar A, Ernst B, Magnani JL, Frenette PS: GMI-1070, a novel pan-selectin antagonist, reverses acute vascular occlusions in sickle cell mice. Blood 2010, 116:1779-1786

97. Field JJ, Majerus E, Gordeuk VR, Gowhari M, Hoppe C, Heeney MM, Achebe M, George A, Chu H, Sheehan B, Puligandla M, Neuberg D, Lin G, Linden J, Nathan DG: Randomized phase 2 trial of regadenoson for treatment of acute vaso-occlusive crises in sickle cell disease. Blood Adv 2017, 1:1645-1649

98. Solovey AA, Solovey AN, Harkness J, Hebbel RP: Modulation of endothelial cell activation in sickle cell disease: a pilot study. Blood 2001, 97:1937-1941

99. Kaul DK, Liu XD, Choong S, Belcher JD, Vercellotti GM, Hebbel RP: Anti-inflammatory therapy ameliorates leukocyte adhesion and microvascular flow abnormalities in transgenic sickle mice. Am J Physiol Heart Circ Physiol 2004, 287:H293-H301

100. Ataga KI, Key NS: Hypercoagulability in sickle cell disease: new approaches to an old problem. Hematology Am Soc Hematol Educ Program 2007:91-96

101. Wajih N, Basu S, Jailwala A, Kim HW, Ostrowski D, Perlegas A, Bolden CA, Buechler NL, Gladwin MT, Caudell DL, Rahbar E, Alexander-Miller MA, Vachharajani V, Kim-Shapiro DB: Potential therapeutic action of nitrite in sickle cell disease. Redox Biol 2017, 12:1026-1039

102. Niihara Y, Koh HA, Tran L, Razon R, Macan H, Stark C, Wun T, Adams-Graves P: A phase 3 study of 1-glutamine therapy for sickle cell anemia and sickle B0-thalassemia. 56th Annual American Society of Hematology Meeting [abstract], December 2014, San Francisco, CA. American Society of Hematology, 2014

103. FDA: FDA Approved L-Glutamine Powder for the Treatment of Sickle Cell Disease. Silver Spring, MD, US Food and Drug Administration, 2017

104. Barst RJ, Mubarak KK, Machado RF, Ataga KI, Benza RL, Castro O, Naeije R, Sood N, Swerdlow PS, Hildesheim M, Gladwin MT; ASSET study group: Exercise capacity and haemodynamics in patients with sickle cell disease with pulmonary hypertension treated with bosentan: results of the ASSET studies. Br J Haematol 2010, 149:426-435 